\title{
Chapter 1 \\ Organisational Identities, Boundaries, and Change Processes of Technical Universities
}

\author{
Katarina Larsen, Lars Geschwind, and Anders Broström
}

\subsection{Technical Universities in Context}

Historically, polytechnic schools rose to prominence in many national settings during the second half of the nineteenth century (Fox and Guagnini 2004). Over time, new areas of technology have been developed and incorporated into their repertoire, and waves of academisation have swept over the former polytechnics, transforming some of them into technical universities (Christensen and Ernø-Kjølhede 2011). Their proud traditions and brands tend to prevail. Several technical universities are included among the most prestigious academic institutions of their nations and the training of engineers and engineering research still enjoy a high level of prestige and national priority, for example in the context of innovation and industrial policy (cf. Clark 1998). Many institutions that might be referred to as technical universities are also held in high regard by industry, and embraced as focal points for regional renewal and development (Lehmann and Menter 2016).

Despite their often formidable success as higher education institutions (HEIs), higher education research has not concerned itself with the study of technically oriented universities as a (potential) organisational category. By no means do we argue that universities within this category of higher education institutions have been entirely absent in previous research. Technical universities feature in studies

\footnotetext{
K. Larsen $(\bowtie)$

Department of Philosophy and History, KTH Royal Institute of Technology,

Stockholm, Sweden

e-mail: katarina.larsen@abe.kth.se

L. Geschwind

Department of Learning in Engineering Sciences, KTH Royal Institute of Technology, Stockholm, Sweden
}

\begin{abstract}
A. Broström
Department of Industrial Economics, KTH Royal Institute of Technology,

Stockholm, Sweden
\end{abstract}

L. Geschwind et al. (eds.), Technical Universities, Higher Education Dynamics 56, https://doi.org/10.1007/978-3-030-50555-4_1 
analysing university-industry interaction in engineering (Perkmann and Walsh 2009) and in historical studies of universities and individual technical universities (Fox and Guagnini 2004). Institutions with a technical profile also play prominent roles in studies discussing relations between scientific ideals and the engineering profession (see, for example, Björck 2016; van der Vleuten et al. 2017; Williams 2002), in studies on the history of engineering education (Jørgensen 2007), as well as in the broader literature on the sociology of higher education (Gumport 2007).

Whereas such previous studies have addressed technical universities in relation to the education of engineers and the provision of engineering education, the starting point for this volume is an interest in technical universities as organisations. Scholarly interest in what HEIs known as 'technical university', 'university of technology', 'institute of technology', or similar have in common today is warranted to better understand historical and contemporary ideals embedded in this type of organisation. Empirically, the volume limits its scope to Europe whilst drawing on experiences from various national contexts, but it also relates to other settings where necessary to understand the respective European settings that the volume engages with.

Since this volume is dedicated to the study of a specific acclaimed category of HEIs, we need to address the issue of specifying how we intend to define this category and its boundaries already at the outset. Is there such a thing as a distinguishable category of HEIs, which we may consider to constitute a field of technical universities? As further explored in specific empirical settings in the empirical chapters in this volume, demarcating such a group of organisations is not a trivial task. For example, to consider the technical university as being 'the place where they educate engineers' (cf Jørgensen 2007) would not seem to be precise enough for our purposes.

A first delineation is based on the traditional academic educational hierarchy. At the first-lowest-level of this hierarchy, we find vocational training for technicians; at the second level there is a more advanced type of engineering education, as typically provided in technical secondary schools and colleges (polytechnics); and at the highest level, we find the highly educated engineers. This latter type of academic education is expected to prepare students for working with technology development, and many such engineers are destined for a leading position in industry or administration. In this the volume focuses on institutions awarding advanced engineering degrees of the latter type, the technical universities and their equivalents (cf Ahlström 2004, p. 116). We are particularly interested in technical universities with both teaching and research as missions and less with teaching-only polytechnics. However, when the role of polytechnics and lower levels of engineering education is challenged and discussed at the higher education "landscape", such as, in this volume, in the binary sectors of Finland and Portugal, or in the unitary of Sweden, this sheds light also on technical universities.

Another dimension that we need to consider is the breadth and scope of the institution. A first suggestion here is that an attempt to delineate what it might mean to be a technical university should not be anchored in a strict disciplinary focus on the field of engineering sciences. The engineering sciences have a long-standing 
relationship with the domain of the natural sciences. Over time, the development of 'fundamental' knowledge about the world has occurred through a dialogue of interdependences between science advances and development in the sphere of 'practical' engineering knowledge, and with the development of technical artefacts and new technologies. At times, the scholars behind advances in engineering and those responsible for major scientific advances have been the very same individuals. Furthermore, in contemporary academia, it is not uncommon for significant projects to require expertise related to both engineering and the sciences-although nowadays this most often implies work in teams involving researchers with different specialisations. Nonetheless, faculties of both engineering and the sciences continue to acknowledge each other's relevance and embrace—or at least do not strongly resist-co-organisation into the same HEI.

Some HEIs that identify themselves as technical universities are single faculty institutions which have a disciplinary focus on engineering science and related natural sciences. The Nordic HEIs Chalmers University of Technology in Gothenburg and the Technical University of Denmark -DTU in Copenhagen are prominent European examples. Other HEIs that, in name and in identity, may be referred to as technical universities are broader, multi-faculty universities. Examples include NTNU - the Norwegian University of Science and Technology in Trondheim or indeed MIT in Boston, USA. HEIs such as these, which were originally more scientifically narrow institutions, have in many cases over time evolved into broader universities through mergers and diversification (see e.g. Chap. 4 in this volume).

In summary, this type of organisation forms a diverse category and has, in the European context, been characterised by idiosyncratic development paths. These paths can be traced to a historical evolution within the respective national setting, but are also clearly affected by international exchange of ideas and templates for institutions (see Chap. 2 in this volume).

Against this background, we adopt a pragmatic approach to the question what institutions are to be considered as technical universities. For the purpose of this volume we consider a HEI whose institutional identity is linked to technically oriented research and advanced education as a technical university.

\subsection{Organisational Identity in Academia}

Laden with values of autonomous scholarship, sceptical inquiry, and deep subject expertise, HEIs do not function as average organisations. To understand them from an organisational perspective, it is essential to tackle issues of identity. Organisational identity shapes strategic action (Brunsson and Sahlin-Andersson 2000; Krücken and Meier 2006; Whitley 2008) and response strategies (Oliver 1991) among universities, in relation to changing internal demands and power groups, and to the state and external stakeholders (cf. Augier and March 2011; Maassen 2000). Other examples of studies from knowledge-intense organisations, such as museums (DiMaggio 1991), emphasise how organisational change can be shaped by 
several-possibly competing-professional identities present within the same organisation. In seeking to study identity processes, extant literature suggests to start in the assumption that organisational identity is communicated through local narratives of HEIs (Kosmützky and Krücken 2015).

Previous studies have emphasised how the identity formation of HEIs is strongly dependent on cross-organisational comparison. The specific mechanisms and underlying logics through which identification with various entities can shape patterns of organisational behaviour have, however, been difficult to pin down. In the case of research on HEIs, research on organisational identity is made inherently difficult by the embeddedness of university activities within several layers of institutional and organisational complexity. With scientific fields and disciplines constituting such strong entities of identification and mediators of values, and with universities being embedded in nested organisational fields of international, national, and regional influence (Hüther and Krücken 2016), it is not clear what room (or need) there is for individual HEIs as organisations to develop strong identities and organisational cultures of their own. To a significant degree, identity in the world of academia is shaped in relation to categories of knowledge and of organisations.

A few studies have discussed what organisational categories that are relevant for historical and contemporary HEIs, and how the boundaries of these categories are being negotiated. For example, Gornitzka and Maassen (2017) recently focused on flagship universities. Another prominent example, which has some parallels to our own effort, is the analysis of Augier and March (2011). They show how business schools in the US underwent a transformation in the early part of the twentieth century, e.g. drawing on principles of 'education must be built on science' which at the time were already being championed in other types of HEIs-notably by institutions adhering to belong to the (potential) organisational category of 'research university'.

\subsection{Organisational Identity and Organisational Categories}

In our study of the 'technical university' as an organisational category, an important starting point is to consider how this category is related to other available categories that may be of relevance for a contemporary HEI. For example: how and why does being perceived as a technical universities differ from what it would entail to be characterised as a comprehensive university, or a research university (Musselin 2006; Maassen and Olsen 2007; Stensaker 2015)?

We conceive of a category of relevance for organisational identity formation to be associated with specific sets of attributes. Relevant attributes for the category technical university may, for example, be 'industry relevance', 'being entrepreneurial' and 'being scientific'. These attributes provide links to and positioning towards other identity category positions, against which a specific position is being assessed. Technical universities may share, for example, the attribute 'industry relevance' with institutions of applied engineering education, and the attribute 'being 
scientific' with the identity position 'research university'. At the same time, the position of 'technical university' may gain status as separate from both these related identity positions by being more strongly associated with industry relevance, than is the comprehensive university, and more strongly associated with 'being scientific' than is the technical institute.

An enquiry about this also prompts questions about how procedures, values, and organisational identity trickle down to and influence the behaviour of individuals in their roles as teachers, researchers and managers. In other words, how professional values are manifested in organisations related to engineering education ('as a teacher at a technical university, I should...') and decisions about research activities ('at technical universities we have a tradition of research in collaboration with industry in areas such as...'). These processes take place both directly (through strategic decisions, implementation of plans etc.) but also indirectly, mediated through the way in which organisational identity is grounded in (typically several) organisational identity categories.

In this context, we consider the orientation towards an organisational category as providing justification for, and being shaped by, different institutional logics in organisations (Ocasio et al. 2015). An organisation can harbour several logics as a counterforce to processes leading to isomorphism and similar looking institutions (DiMaggio and Powell 1983). Furthermore, a certain level of autonomy (achieved through, for example, excellence and/or industrial relevance criteria) can in turn safeguard practices and vocabularies used by the different units within an organisation such as the example of competence centres or centres of excellence hosted by university organisations that also have strong ties to industry (Larsen 2019). Chapters 2 and 8 in this volume describe how tensions between engineering as practice and engineering as scientific discipline characterise the development of HEIs referred to as technical universities. Identity work drawing on the position of technical university has from time to time sought to maintain and develop a balance between these two values. Thus, we may understand 'technical university' as an organisational category that harbours and enables an institutionalised compromise between potentially conflicting logics. Furthermore, the attributes and boundaries of an organisational category can be understood as being negotiated by the actors and interests that constitute an organisational field (Powell and DiMaggio 1991; Wooten and Hoffman 2017), which in themselves "are certainly the result of human activity but are not necessarily the products of conscious design" (Powell and DiMaggio 1991, p. 8). This brings us to also recognise that the technical universities, on the one hand, respond to external influences but, on the other hand are guided by internal processes of identity formation and reshaping of ideals, categories and boundaries. These boundaries are shaped in interaction between universities and knowledge intensive organisations including industry and are creating interfaces between ideals in academia and commercial logics and ideals (Murray 2010). At the same time, the organisational boundary between the external and internal can, in turn, become more permeable when organisations try to access critical knowledge and skills (Powell and Soppe 2015) through collaborative projects and exchange. 


\subsection{Localized and International Negotiations on Institutional Change}

The idea (and ideal) of what it means to be a technical university is to a significant extent shaped by national contexts, as further explored in the chapters about Poland (Chap. 5) and Germany (Chap. 7) in this volume. That is, universities are grounded in national institutional frameworks (Fagerberg et al. 2009), which may differ in terms of historical contexts, and education and science policy reforms. However, the notion of 'technical university' as an organisational identity category is, in an important way, subject to internationally oriented mimetic processes. Such mimetic influence is exerted by globally visible role models or (as illustrated in Chap. 6 on OECD advice regarding technical universities) through ideas that travel through international institutional benchmarking (Pinheiro and Stensaker 2014). Hence, while technical universities have different roles, organisational structure, and traditions in different countries, they are also expected to share common roots, and to be subject to related external expectations and influences. With globalisation, they are also increasingly addressing the same audiences: internationally mobile students and faculty, and international bodies involved in policy development.

However, in the absence of strong templates representing a specific category (such as technical university), isomorphic development may dilute existing categories at the expense of others or alternatively, merger processes of higher education institutions can catalyse processes of voicing and redefining what the distinctive characteristics are. What will be the position of HEIs currently identified as technical universities within university systems in the decades to come? Will being a technical university appear as attractive to newly started or re-orienting HEIs? The central ambition behind this volume is to provide underpinning to a discussion of these issues by providing a comprehensive analysis of what organisational traits and ideals are associated with the term technical university in contemporary societies. This encompasses a discussion (based on empirical cases) concerned with how the organisational identities of technical universities are influenced by internal and external factors and activities carried out in collaboration with industrial actors and other HEIs relating to core activities, including engineering education, and research activities. Thereby, it seeks to provide a basis for a discussion on what it means to be a technical university in the twenty-first century and beyond.

\subsection{Co-existing and Competing Ideals of Technical Universities}

As further developed in other parts of this volume, the broad research university is by many seen as the leading ideal for HEIs. So how attractive is it for contemporary European HEIs to be oriented towards the more focused category 'technical university'? This question is theoretically linked to a more general set of questions about 
how organisations such as HEIs can adapt to (or resist) the influence of global templates defining a set of well-defined categories and associated organisational traits. Can diversity in terms of these traits that are developed locally prevail, despite standardisation efforts at an international or global level?

Some studies of universities apply sociological concepts, such as diversity, recognition, and local order to discuss ideal types applicable to comparative inquiry, concluding that 'standardization according to a global hierarchical institutional order may coexist with diversity' (Thoenig and Paradeise 2018, p. 197). This is an important observation since it suggests a need to study how organisations respond to multiple logics and institutional complexity (Greenwood et al. 2010) and how identity categories are communicated internally and externally by organisations (Ocasio et al. 2015). A theoretical point of departure in contemporary organisational studies is to acknowledge organisational narratives and discourses rooted in locally anchored values as being of key relevance to understanding identity formation, inertia, and actions of organisations (Gabriel 2004). In particular, studies of decisionmaking in situations dealing with dilemmas (when logics clash) and paradoxes are called for to understand sense-making processes more clearly in organisations (Weick 1995). This is relevant for the analysis of coupling between policy and daily practices of organisations and, as a concrete example, how organisational practices of engineering education can undergo processes of academic drift (Harwood 2010), while still remaining relevant to societal expectations and the demand for traditional skills associated with engineering education and technical universities. In the context of this volume, we are led to ask how different co-existing ideals regarding the organisational form of a HEI with a strong engineering tradition may play out in internal and external negotiations. In other words, an overarching question driving our research is what it means to be, or not to be, a technical university.

\subsection{Are Technical Universities Essentially Different...?}

Throughout this volume, organisational traits and ideals anchored in the identity and organisational category technical university are studied. At this point, the reader may ask why we suggest that understanding whether a HEI does or does not orient itself against a given category is an important question to consider. For example,

\footnotetext{
what reasons would we have to expect engineering science and engineering education to be enacted in a different way if performed in the organisational context of a HEI with an organisational identity leaning towards the notion of 'technical university', compared to the corresponding activities being performed at a technical faculty embedded in a large, multi-faculty university?
}

Our general take on this question is that a 'technical university' can be expected to be permeated by culture derived from the context of engineering. For example, we note a tendency of single-faculty technical universities to set up organisational structures that are less clearly drawn along disciplinary boundaries, than what is the 
case in many traditional multi-faculty universities. It may also be expected that the actions and behaviour of university leadership figures and administrators will be shaped by norms and ideals related to organisational identity, and thereby to available categories.

In a 'classical' university setting, actors have to balance a multitude of disciplinary cultures and traditions. In an organisation where an engineering-dominated culture prevails, leaders may be expected to be more unrestrained e.g. in regard to prioritisation and in shaping relationships to external actors (Broström et al. 2019).

These arguments are congruent with how the identity and institutional history of other specialised HEIs (such as business schools and medical schools) have been analysed in previous scholarly work. Both types of HEIs, in what seems to be a relevant parallel to technical universities, have relatively strong and separable organisational identities rooted in practices, routines, and rituals. Specifically, Augier and March's (2011) work on the US-based business schools as a particular type of organisation emphasises the context of change and the roots of change.

We find the argument that organisational forms also matter for the performance and choice of direction in academic activities convincing enough to motivate the study of technical universities as an at least partially separable group. However, whether a specific HEI has more or less in common with one or the other HEI (for example, if technical university $\mathrm{X}$ has more or less in common with technical university $\mathrm{Y}$ or comprehensive university Z) is essentially an empirical question. Readers of this volume will find several discussions regarding sameness and difference across the different chapters. One example is the chapter by Vellamo et al. discussing organisational identity as a collective identity and distinctive characteristics (based on the organisation's collective "we" rather than individual identities within the organisation). That study focuses on technical identity in a merger process through analysis of characteristics that particularly set the organisation as different from other (similar) organisations (Albert and Whetten 1985). This highlights how organisational identity of technical universities can be articulated and narrated under processes of change. Rather than providing a definite answer to the question on what basis a HEI is to be included or excluded from the category of a 'true technical university', the empirical analysis focuses on identity formation processes but is nevertheless informed about ideas (and ideals) associated with technical universities.

\subsection{The Volume's Approach}

Our point of departure for this volume is a view of changing academic realities, through which an identity as a technical university is challenged and reconstituted. The idea of what is entailed in being a technical university evolves over time in response to changes in the structure and dimensioning of national higher education systems, to changes in the disciplinary basis of academic research, and to changes in the governance, organisation and funding of HEIs. 
This volume should be seen as representing a mission to cover some of the ground for empirical analysis and provide some theoretical points of departure for a conceptual discussion about the past, present, and future of the technical university. Our ambition is to offer an empirically grounded analysis of cases in the European context to provide a foundation for discussion about future positioning and strategic development. Our main business, however, is with the present. To provide an analysis of what it means to be a technical university, and how influential ideals associated with that particular category affect the actions and reactions of university stakeholders, a number of empirical and conceptual studies are conducted. These studies are set in different national settings including Germany, Finland, Norway, Portugal, Poland, Sweden, and Switzerland.

Chapters $3,4,5,6,7,8,9,10$, and 11 which constitute the bulk of this volume, are independent studies selected and designed to allow insights into how the notion of the technical university is mobilised in times of change within HEIs. The individual chapter contributions display a wide array of theoretical perspectives, although they share the focus on the identity of technical universities. The chapters contribute in different ways to the broader discussion about how change and stability of existing organisational identity arise. Further, they discuss different ways that tension arises through internal reforms negotiating the boundaries of the organisation, but also through external pressures envisaged through reforms initiated from the outside. They discuss coercive change initiated through regulatory reforms, as well as processes of imitation or isomorphism to resemble other HEIs with which the technical university wishes to be associated, or share its similar core identity (DiMaggio and Powell 1983). Theoretical perspectives and methodology differ between chapters, reflecting their shifting foci.

Overall, the volume addresses two main lines of inquiry, both related to the organisational identity of technical universities: (a) formation of ideals and boundaries and (b) responses to change and how it relates to formation and re-negotiations of identity. The chapters in the volume are concerned with how technical universities respond to external influences but also are guided by internal processes of identity formation and reshaping of ideals and boundaries. This focus represents two research strategies to uncover key elements of organisational identity and the mobilisation and renegotiations of the boundaries and elements of organisational categories.

The first of these strategies is to analyse institutional responses to external pressure at HEIs defining themselves as technical universities. Studies following this approach are reported in Chaps. 3, 4, 5, and 6. These chapters offer in-depth studies of the reactions to external initiatives aimed at affecting how HEIs in general and technical universities in particular manage their teaching and research activities. In particular, the chapters explore how different national-level reforms and processes of institutional isomorphism play out at the organisational level.

The study reported in Chap. 3 considers the different traits and heterogeneity of technical universities and their consequences, drawing on a study of technical universities in Europe, including Denmark, Sweden and Switzerland. The analysis includes a discussion about scientific impact profiles and their alignment with 
government steering, funding, and internal organisation and leadership. Despite sharing some similar traits and (on the surface) appearing similar-in the sense of providing professional training of engineers in the range of areas that fall under the epistemic and organisational category of 'engineering' - the chapter concludes that they configure tasks and roles differently. Moreover, their scientific impact profiles should be considered in a wider national context, where technical universities serve different purposes and have a variety of collaborative alliances with industry partners and public sector organisations.

Chapter 4 is set in the technical university in Trondheim (NTNU), which has historically, and in terms of number of engineering students, played a prominent role in the Norwegian higher education system. Due to mergers, NTNU now covers most academic fields, including the humanities, social sciences, medicine, and law. However, as illustrated by the chapter, STEM disciplines (science, technology, engineering, and mathematics) continue to dominate. Thus, one the one hand, the study raises questions about strategic steering of a technical university in relation to national priorities in STEM disciplines, and on the other hand the autonomy of a technical university, which has a broad profile including disciplines of social sciences and humanities that go beyond traditional engineering disciplines.

The historical analysis of technical universities in Poland, presented in Chap. 5, provides an insight into traditional roles of technical universities in providing professional training in engineering, and the rise of technical universities as an educational institution with close ties to industry, and as a non-elite educational institution. Three phases are identified that link to industrial development in Poland in the late nineteenth century, followed by a phase after the Second World War to create new expertise and industrial centres in areas of engineering and agriculture. Following this expansion, the 1960-70s is linked to the expansion of higher education in Poland resulting in technical universities evolving from the already established engineering schools in Poland.

In many countries, formalisation of institutional categories plays an important role in creating and maintaining differences between HEIs. Chapter 6 draws on experiences from two national contexts, Portugal and Finland, to address questions regarding the mission of higher education systems in advancing binary ideals of distinct roles for technical universities and polytechnics. The distinct national contexts are contrasted with international scripts suggested by advice from international organisations such as the OECD for introducing change or suggesting continuity through a reinforcement of differentiated higher education systems in the two countries studied.

The second main line of enquiry of the volume, which is presented in Chaps. 7, $8,9,10$, and 11 , is to study identity formation at technical universities through the lens of how internal processes of the organisation drive changes of how the organisational boundaries are defined. These analyses are empirically rooted in studies of historical and contemporary discussions about changing the organisation of engineering research and education. Specifically, the chapters in this volume that examine mergers between higher education institutions, the introduction of new curricula deviating from the tradition of advanced studies in engineering, and the 
establishment of new organisational entities within technically oriented universities. Utilising the mobilisation of identity issues brought about by suggestions for change, the chapters study boundary work-or the lack thereof-by key actors. Such boundaries particularly concern the demarcation between academia and (industrial/technological) practice, and curricular strategies (for example, concerning the relationship between knowledge based clearly within the domain of engineering science and other knowledge bases). In doing so, the chapters provide insights into the construction of organisational identity and institutional boundaries at technical universities.

The analysis in Chap. 7 addresses the justification of technical universities in Germany by discussing the compromises of the civic-industrial order, focusing on the products of research and teaching as competitive public services. By scrutinising the situation in technical universities, the temporary stability of the civicindustrial order and the dynamic challenges of the market order can be analysed for the period 2000-2014. In a related enquiry about the relationship between academic and professional values in technical universities, Chap. 8 discusses an important developmental initiative in the area of engineering education: the 'conceive, design, implement, operate' (CDIO) framework. This analysis draws on the concept of integrated curriculum, which is based on experiences from the mechanical engineering programme at Chalmers University of Technology in Sweden. Further, it discusses implications at both curriculum and organisational levels of the technical university.

Chapter 9 analyses processes of identity formation during an ongoing merger process in Tampere, Finland. The historical backdrop to the Finnish case of technical universities is that the field of technical/industrial education was, in the late nineteenth century, nationally defined in terms of content, level, and qualification. Identity is understood as a collective social concept, where being part of a group is important for individual identity, and group identity is considered in relation to other groups (representing other identities). In the context of technical universities, the process of organisational mergers therefore poses questions about how an engineering identity (associated with a technical university) is preserved or evolves within a merger process resulting in a new university with a broader scope of disciplines represented.

The issue of change processes and identity is also addressed in Chap. 10, through an analysis of engineering academisation based on a study of an externally initiated process to reform engineering education in Sweden. Experiences from technical universities show that organisational identity was anchored in both the research and master's programmes and that this also affected the internal responses to change (or resistance to transformation). This resulted in a strategically designed initiative of a dual engineering education system within the leading technical universities that preserved or even strengthened the existing identity in the organisation of engineering programmes. Chapter 11 discusses the introduction of new curricula into technical universities. Specifically, the chapter studies how double degree programmes in engineering and teaching were set up at the two largest and oldest technical universities in Sweden. 
The broader themes of the volume and insights from the different chapters are brought together in the concluding chapter, where the focus shifts from experiences of contemporary higher education institutions and systems to the world of ideas and conceptual understanding of technical universities. Thus, we seek to draw on our amassed insights from the past and present of technical universities to gaze into the (near) future. The volume concludes with an analysis of the content of the identity category 'technical university' and a discussion about contemporary categories and future prospective trajectories of technical universities.

\section{References}

Ahlström, G. (2004). Technical education, engineering, and industrial growth: Sweden in the nineteenth and early twentieth centuries. In R. Fox \& A. Guagnini (Eds.), Education, technology and industrial performance in Europe 1850-1939 (pp. 115-140). Cambridge: Cambridge University Press.

Albert, S., \& Whetten, D. A. (1985). Organizational identity. In L. L. Cummings \& B. M. Staw (Eds.), Research in organizational behavior (Vol. 14, pp. 263-295). Greenwich: JAI.

Augier, M., \& March, J. G. (2011). The roots, rituals and rhetorics of change. North American business schools after the Second World War. Stanford: Stanford University Press.

Björck, H. (2016). A distinguished scientific field? Pursuing resources and building institutions for engineering research in Sweden, 1890-1945. History and Technology, 32(4), 315-348.

Broström, A., Feldmann, A., \& Kaulio, M. (2019). Structured relations between higher education institutions and external organisations: Opportunity or bureaucratisation? Higher Education, 78(4), 575-591.

Brunsson, N., \& Sahlin-Andersson, K. (2000). Constructing organizations: The example of public sector reform. Organization Studies, 21(4), 721-746.

Christensen, S. H., \& Ernø-Kjølhede, E. (2011). Academic drift in Danish professional engineering education. Myth or reality? Opportunity or threat? European Journal of Engineering Education, 36(3), 285-299.

Clark, B. R. (1998). Creating entrepreneurial universities: Organizational pathways of transformation (Issues in higher education). New York: Elsevier.

DiMaggio, P. (1991). Constructing an organizational field as a professional project: U.S. art museums, 1920-1940. Chapter 11, In: W. W. Powell, \& DiMaggio, (Eds.). The New Institutionalism in Organizational Analysis. Chicago/London: Chicago University Press.

DiMaggio, P. J., \& Powell, W. W. (1983). The iron cage revisited: Institutional isomorphism and collective rationality in organizational fields. American Sociological Review, 48(2), 147-160.

Fagerberg, J., Mowery, D. C., \& Verspagen, B. (2009). Innovation, path dependency and policy. The Norwegian case. Oxford: Oxford University Press.

Fox, R., \& Guagnini, A. (Eds.). (2004). Education, technology and industrial performance in Europe 1850-1939. Cambridge: Cambridge University Press.

Gabriel, Y. (Ed.). (2004). Myths, stories, and organizations: Premodern narratives for our times. Oxford: Oxford University Press.

Gornitzka, Å., \& Maassen, P. (2017). European flagship universities: Autonomy and change. Higher Education Quarterly, 71(3), 231-238.

Greenwood, R., Magán Díaz, A., et al. (2010). The multiplicity of institutional logics and the heterogeneity of organizational responses. Organization Science, 21(2), 521-539.

Gumport, P. J. (Ed.). (2007). Sociology of higher education. Baltimore: The Johns Hopkins University Press.

Harwood, J. (2010). Understanding academic drift: On the institutional dynamics of higher technical and professional education. Minerva, 48(4), 413-427. 
Hüther, O., \& Krücken, G. (2016). Nested organizational fields: Isomorphism and differentiation among European universities. In E. P. Berman \& C. Paradeise (Eds.), The university under pressure (pp. 53-83). Bingley: Emerald Group Publishing Limited.

Jørgensen, U. (2007). Historical accounts of engineering education. In E. Crawley, J. Malmqvist, S. Ostlund, D. Brodeur, \& K. Edstrom (Eds.), Rethinking engineering education. The CDIO approach (pp. 216-240). Boston: Springer.

Kosmützky, A., \& Krücken, G. (2015). Sameness and difference, analyzing institutional and organizational specificities of universities through mission statements. International Studies of Management and Organization, 45(2), 137-149.

Krücken, G., \& Meier, F. (2006). Turning the university into an organizational actor. In G. S. Drori, J. W. Meyer, \& H. Hwang (Eds.), Globalization and organization: World Society and organizational change (pp. 241-257). Oxford: Oxford University Press.

Larsen, K. (2019). Managing the complexity of centres of excellence: Accommodating diversity in institutional logics. Special issue: Performance management and mission diversity in higher education. Tertiary Education and Management. https://doi.org/10.1007/s11233-019-09053-w.

Lehmann, E., \& Menter, M. (2016). University-industry collaboration and regional wealth. Journal of Technology Transfer, 41(6), 1284-1307.

Maassen, P. (2000). The changing roles of stakeholders in Dutch university governance. European Journal of Education, 35(4), 449-464.

Maassen, P., \& Olsen, J. P. (Eds.). (2007). University dynamics and European integration. Dordrecht: Springer.

Murray, F. (2010). The oncomouse that roared: Hybrid exchange strategies as a source of distinction at the boundary of overlapping institutions. American Journal of Sociology, 116(2), 341-388.

Musselin, C. (2006). Are universities specific organisations? In G. Krücken, A. Kosmützky, \& M. Torka (Eds.), Towards a multiversity? Universities between global trends and national traditions (pp. 63-84). Bielefeld: Transcript Verlag.

Ocasio, W., Lowenstein, J., \& Nigam, A. (2015). How streams of communication produce and change institutional logics: The role of categories. Academy of Management Review, 40(1), 28-48.

Oliver, C. (1991). Strategic responses to institutional processes. Academy of Management Review, $16(1), 145-179$.

Perkmann, M., \& Walsh, K. (2009). The two faces of collaboration: Impacts of university-industry relations on public research. Industrial and Corporate Change, 18(6), 1033-1065.

Pinheiro, R., \& Stensaker, B. (2014). Designing the entrepreneurial university: The interpretation of a global idea. Public Organization Review, 14(4), 497-516.

Powell, W. W., \& DiMaggio, P. (Eds.). (1991). The new institutionalism in organizational analysis. Chicago: University of Chicago Press.

Powell, W. W., \& Soppe, B. (2015). Boundaries and new organization forms. In International encyclopedia of the social \& behavioral sciences (pp. 768-777). Amsterdam: Elsevier.

Stensaker, B. (2015). Organizational identity as a concept for understanding university dynamics. Higher Education, 69(1), 103-115.

Thoenig, J.-C., \& Paradeise, C. (2018). Higher education institutions as strategic actors. European Review, 26(1), 57-69.

van der Vleuten, E., Oldenziel, R., \& Davids, M. (2017). Engineering the future, understanding the past: A social history of technology. Amsterdam: Amsterdam University Press.

Weick, K. E. (1995). Sensemaking in organizations. London: Sage.

Whitley, R. (2008). Construction universities as strategic actors: Limitations and variations (No. 557). Manchester: Manchester Business School Working Paper.

Williams, R. (2002). Retooling. A historian confronts technological change. Cambridge, MA: The MIT Press.

Wooten, M., \& Hoffman, A. J. (2017). Organizational fields: Past, present and future. In R. Greenwood, C. Oliver, K. Sahlin, \& R. Suddaby (Eds.), SAGE handbook of organizational institutionalism (pp. 130-148). London: SAGE. 
Open Access This chapter is licensed under the terms of the Creative Commons Attribution 4.0 International License (http://creativecommons.org/licenses/by/4.0/), which permits use, sharing, adaptation, distribution and reproduction in any medium or format, as long as you give appropriate credit to the original author(s) and the source, provide a link to the Creative Commons license and indicate if changes were made.

The images or other third party material in this chapter are included in the chapter's Creative Commons license, unless indicated otherwise in a credit line to the material. If material is not included in the chapter's Creative Commons license and your intended use is not permitted by statutory regulation or exceeds the permitted use, you will need to obtain permission directly from the copyright holder. 